\title{
RENÚNCIA DO DIREITO FUNDAMENTAL PELO TRABALHADOR
}

\author{
WAIVER OF FUNDAMENTAL RIGHT BY THE EMPLOYEE
}

Edilton Meireles de Oliveira Santos

\begin{abstract}
Pós-doutor em Direito pela Faculdade de Direito da Universidade de Lisboa. Doutor em Direito pela Pontifícia Universidade Católica de São Paulo (PUC/SP). Professor de Direito Processual Civil na Universidade Federal da Bahia (UFBa). Professor de Direito na Universidade Católica do Salvador (UCSal). Desembargador do Trabalho na Bahia (TRT

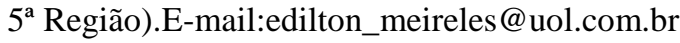

Recebido em: 07/04/2017 Aprovado em: 06/07/2018

RESUMO: O presente trabalho teve por objetivo analisar a possibilidade de o trabalhador renunciar o exercício dos direitos fundamentais no curso da relação de emprego. Debateu-se a possibilidade de extrair do poder de direção do empregador a possibilidade de se restringir e limitar o direito fundamental do trabalhador. Analisou-se, ainda, a possibilidade de renúncia, restrição ou limites aos direitos fundamentais sem a manifestação expressa do detentor da proteção e garantia constitucional e a limitação ao direito fundamental por norma coletiva. Concluiu-se que que o simples poder de direção e de fiscalização não assegura ao empregador o direito de limitar ou restringir os direitos fundamentais dos trabalhadores numa relação de emprego. Neste trabalho foi utilizado, a partir da revisão da literatura e da pesquisa jurisprudencial, o método dedutivo, optando-se pela pesquisa na área da ciência dogmática do Direito.

Palavras-Chave:renúncia - direitos fundamentais - empregado - relação de emprego

ABSTRACT: The objective of this study was to analyze the possibility of the worker to renounce the exercise of fundamental rights in the course of the employment relationship. It was discussed the possibility of extracting from the power of management of the employer the possibility of restricting and limiting the fundamental right of the worker. The possibility of renunciation, restriction or limits to fundamental rights was also analyzed without the express manifestation of the holder of the protection and constitutional guarantee and the limitation to the fundamental right by collective norm. It was concluded that the mere power of management and supervision does not ensure the employer the right to limit or restrict the fundamental rights of workers in an employment relationship. In this work, the deductive method was used, based on literature review and jurisprudential research, opting for research in the field of dogmatic law science.

Keywords: waiver - fundamental rights - employee - employment relationship

SUMÁRIO. 1. Introdução. 2. Do poder diretivo e fiscalizador. 3. Renúncia a direito fundamental. 4. Limitação ao direito fundamental mediante negociação coletiva. 5. Princípio do não retrocesso social. 6. Conclusão. 7. Referências. 


\section{Introdução}

É muito comum, na relação de emprego, por diversas razões, o trabalhador sofrer restrição aos seus direitos fundamentais. Muitas dessas restrições, porém, são fruto de pactos contratuais, ao invés de simples imposições do empregador.

No caso de restrições impostas pelo empregador sem prévia manifestação ou acerto negocial com o trabalhador, pode-se, facilmente, concluir pela ilicitude da limitação ao direito fundamental até por ausência da vontade do detentor do direito fundamental violado. A problemática, porém, surge quando a restrição é fruto de acerto contratual, ainda que tácito. É o caso, por exemplo, do trabalhador que concorda em ser revistado pelo empregador, abrindo mão do seu direito fundamental do respeito à vida íntima ou privacidade. Parte da doutrina, porém, entende que, com a celebração do contrato de emprego, o trabalhador estaria concordando que seus direitos fundamentais fossem limitados dado o poder de direção conferido ao empregador.

Neste trabalho procuramos delinear as regras e procedimentos que devem ser observadas para eventual validade desses acertos contratuais, apreciando a corrente doutrinária que entende que o trabalhador concorda com a cessão do direito fundamental ao ingressar no quadro social da empresa em confronto com as posições contrárias.

$\mathrm{O}$ estudo se justifica em face da incerteza ainda vigente em relação à possibilidade de se restringir direitos fundamentais dos empregados no curso da relação de emprego, o que gera insegurança jurídica. Há incerteza, ainda, quanto ao procedimento a ser adotado para a efetivação da restrição ou mesmo os instrumentos jurídicos que podem ser utilizados.

$\mathrm{Na}$ pesquisa foi utilizado o método dedutivo, com revisão da literatura e análise da praxis (jurisprudência), em estudo qualitativo.

\section{Do poder diretivo e fiscalizador}

A CLT, em seu art. 442, ao dispor que o "Contrato individual de trabalho é o acordo tácito ou expresso, correspondente à relação de emprego" deixa claro que o pacto firmado entre empregado e empregador tem natureza contratual (BRASIL, 1943). Cumpre ressaltar, no entanto, e porque relevante para as teses que se pretende demonstrar, que se trata de contrato que tem como objeto um direito fundamental social - o direito ao trabalho -, que é um dos instrumentos de concretização da dignidade da pessoa humana.

Em assim sendo, não se lhe aplicam à essa espécie de contrato de forma plena os princípios gerais dos contratos, próprios dos ajustes em que predominam os interesses meramente privados. Isso porque o contrato de emprego está submetido ao regime dos direitos fundamentais sociais. Sua base maior está no art. $7^{\circ}$ da Constituição brasileira, quando este dispõe sobre diversos direitos dos trabalhadores (BRASIL, 1988). Aliás, um dos poucos contratos com claro assento na Constituição, já que destinatário de diversas regras de proteção e garantias postas na Carta Magna.

Teorias que procuram atribuir à relação de emprego natureza jurídica diversa da contratual, por sua vez, estão superadas, não só no Brasil, como nos demais países onde impera o Estado Democrático de Direito, sejam eles de matriz jurídica romano-germânica ou de commonlaw. Essas outras teorias conquistaram a simpatia de diversos doutrinadores, tendo sido adotadas em algumas legislações, já revogadas, certamente por influência do clima político dominante em cada momento histórico (PEREIRA, 1991, p. 17). E, é certo, que ainda hoje encontram adeptos no Brasil, já que veem os trabalhadores muito mais como objeto do contrato de emprego do que como verdadeiramente uma das partes contratante.

Dentre essas outras teorias se destaca a institucional. Por ela se entende que entre empregado e empregador há uma relação institucional decorrente da integração do trabalhador nos quadros da empresa. Forma-se uma relação institucional e não, contratual. O trabalhador, 
assim, fica submetido ao empregador conforme modelo hierárquico, sujeitando-se às condições de trabalho previamente estabelecidas, apenas se sujeitando a elas (PEREIRA, 1991, p. 18).

Amauri Mascaro Nascimento (1989, p. 278) sustenta que, neste caso, o empregado se submete a uma verdadeira relação estatutária, na qual sua vontade pouco importa. Lembra, também, Amauri Mascaro Nascimento (1989, p. 278), que essa teoria foi aceita na França, acolhendo integralmente os ensinamentos alemães (SUPIOT, 2002, p. 21),

Pode-se afirmar, pelas lições dos institucionalistas, que o empregado se vincularia ao empregador numa verdadeira relação estatutária, daí porque sujeito ao poder diretivo e disciplinar deste último. Instituição essa próxima das organizações de natureza militar, que se amparam nos princípios da hierarquia e da disciplina. Dela, por sua vez, derivou a teoria comunitária (da empresa como uma comunidade) e autoritária (da empresa como espaço do exercício da autoridade do empregador) (QUINTAS, 2013, p. 64). Esta teoria floresceu aos ventos das ideias do nacional-socialismo (nazismo) na Alemanha (MASCARO, 1998, p. 266), expandindo-se para a Itália e França onde encontraram simpatizantes das ideias fascistas e autoritárias (DELGADO, 1996, p. 183). Era fruto, pois, da ideologia dominante à época, em especial nos anos 30 e 40 do século XX (MORAES, 1976, p. 81). Na Espanha, essas teorias predominaram durante todo período franquista, findo em 1978 (BAYLOS, 1999, p. 63).

Esse ideal, por sua vez, alcançou o apogeu

a época do nacional-socialismo. Com base na doutrina de Adolf Hitler, exposta em Minha luta (Mein Kampf) 81, foi promulgada em 20 de janeiro de 1934 a lei sobre a ordenação do trabalho nacional (Gesetz zur Ordnung der Nationalen Arbeit), cujo art. $1^{\circ}$ reza: "Na empresa trabalham em comum o empresário como chefe de empresa, os empregados e operários como pessoal (Gefolgschaft) com vistas à realização dos fins da empresa e para o bem comum do povo e do estado". Prevalecia a noção de comunidade de empresa, considerada "uma associação viva entre pessoas unidas pelo trabalho em comum, e não uma reunião de fato entre indivíduos". A grande antítese padrão-operário desaparece. Comunidade da empresa significa o fim da luta de classes. O empresário é o chefe natural (Führerprinzip) e a este título exerce sobre os subordinados autoridade absoluta, indispensável, segundo as ideias hitlerianas, para que uma obra comum possa ser levada a cabo. A comunidade de empresa era assim definida: "Werksgemeinschaft significa a união orgânica de todas as forças vivas que agem na empresa, com a finalidade de realizar em comum os fins da empresa". Até o vocabulário é alterado: empregador (Arbeitgeber), empregado (Arbeitnehmer), mercado de trabalho (Arbeitmarkt), todos os termos da feição materialista são substituídos por outros, de caráter mais moral e idealista: Führer, Gefolgsmann, Arbeitseinsatz, etc. O contrato de trabalho (Arbeitsvertrag) é eclipsado pela "relação de trabalho" (Arbeitsverhältnis) (ROMITA, 2014, p. 941).

Contudo, como adverte Arion Sayão Romita (2014, p. 942), mesmo após o fím do regime nazista, as suas ideias acabaram por contaminar o direito do trabalho brasileiro. Tal teoria, por conseguinte, teve reflexos entre os doutrinadores brasileiros a ponto de os próprios membros da Comissão elaboradora do Projeto de Consolidação das Leis de Proteção do Trabalho, instituída pelo então Presidente Getúlio Vargas, em dezembro de 1942, terem feito expressa opção pela teoria da instituição ou estatutária, com respaldo nas teses de Maurice Hauriou e Georges Renard (SÜSSEKIND, 1943, p. 358).

Vale lembrar que o professor Maurice Hauriou, professor da Universidade de Toulouse, publicou sua La Théorie de 1'Institution et de la Fondation em 1925. Já Georges Renard, professor da Universidade de Nancy, escreveu sua La Théorie de 1'Institution em 1930 e, 
posteriormente, La Philosophie de 1'Institution em 1939, ou seja, todas estas obras foram lançadas quando predominavam na Europa as ideias fascistas, que tendiam a implantar uma organização ao estilo militar (hierarquia e disciplina) em todas as instituições.

Em suma, nasceu, difundiu-se e se propagou a teoria institucionalista a reboque das ideias autoritárias que predominavam nos anos das décadas de 30 e 40 do século XX, na Europa, em especial, com repercussão no Brasil à época da ditadura Vargas (CATHARINO, 1972, p. 222; MORAES, 1986, p. 251; BAYLOS, 1999, p. 63; SUPIOT, 2002, p. 13).

Vale ressaltar, porém, que, a rigor, a Comissão elaboradora da CLT, composta por Rêgo Monteiro, Segadas Viana, Arnaldo Süssekind e Dorval Lacerda, não fez uma opção pelo institucionalismo radical, conforme sua raiz alemã, mas sim para o que o professor José Martins Catharino (1972, p. 235) denominou de institucionalismo impuro ou moderado. Em suma, não negam a contratualidade do ingresso do empregado na empresa, mas afirmam os adeptos dessa corrente que o direito institucional prevalece sobre o contratual, e a este ainda antecede. Neste caso, então, o contrato apenas serviria de porta de acesso à empresa, concebida como uma instituição. Assim, a relação de emprego seria sempre institucional, ainda que, na forma, fosse contratual (CATHARINO, 1972, p. 235).

Assim, é certo que, apesar de aceita predominantemente a teoria contratualista, e ultrapassada a concepção doutrinária institucionalista "de evidente inspiração nazifascista" (ROMITA, 2014, p. 957), ainda assim seu pensamento (institucional) influenciou e contribuiu para a definição de alguns institutos jurídicos inerentes à relação de emprego no Brasil (ROMITA, 2001; 2014, p. 932). Entre estes, devemos destacar os principais, qual sejam, a definição do que seja subordinação jurídica e os poderes que dela decorrem.

Cabe ressaltar, porém, que a doutrina hoje predominante entende e revelou, a partir de uma melhor compreensão do negócio jurídico firmado pelo empregado e empregador, que a subordinação jurídica decorre de cláusula contratual pela qual o empregado se obriga a obedecer às ordens do empregador na direção dos serviços prestados e para os quais foi contratado.

Por subordinação jurídica, desse modo, entende-se a sujeição do empregado às ordens dadas pelo empregador para cumprimento da tarefa para qual aquele se obrigou a executar. $\mathrm{O}$ empregado, ao ser contratado, passa a ficar subordinado ao empregador, recebendo ordens (poder diretivo), mas apenas para execução das atividades contratadas. Essa condição contratada entre empregado e empregador - de subordinação jurídica -, no entanto, deve ser entendida e compreendida em seu verdadeiro sentido, na medida do pactuado.

A subordinação jurídica, assim, significa que o empregador, por exercer o poder de direção da atividade econômica ou mesmo quando não exerce atividade econômica, mas dirige o serviço prestado pelo empregado (numa relação doméstica, por exemplo), reserva-se, por contrato firmado com o trabalhador, ao direito de dar ordens e de dirigir a prestação dos serviços contratados. "Não se trataria de um poder sobre a pessoa do empregado, senão sobre o objeto do contrato, limitado sempre à observância da dignidade da pessoa trabalhadora" (COUTINHO, 2000, p. 46). Cuida-se de dirigir a prestação de serviços e não propriamente a vida (corpo e alma) do trabalhador.

A doutrina, porém, procura dividir esse poder de direção (em seu sentido amplo) em, pelo menos, três vertentes: diretivo (stricto sensu), regulamentar e disciplinar (MAGANO, 1988, p. 166). Maurício Godinho Delgado (1999, p. 132) enfeixa, mais sistematicamente, esses poderes na expressão poder empregatício, que seria o "conjunto de prerrogativas com respeito à direção, regulamentação, fiscalização e disciplinamento da economia interna à empresa e correspondente prestação de serviços". O poder empregatício envolveria, assim, o poder diretivo, o poder regulamentar, o poder fiscalizatório e o poder disciplinar (DELGADO, 1999, p. 132).

Luiz José de Mesquita (1991, p. 39) menciona, além daqueles três poderes (diretivo, regulamentar e disciplinar), o poder hierárquico. O poder hierárquico seria aquele conferido ao 
empregador por este se colocar em patamar superior ao empregado, que lhe é subordinado na prestação de serviços.

O poder diretivo em sentido restrito, como mencionado acima, é o direito do empregador ditar ordens e, obviamente, fiscalizar os serviços contratados. Já o poder regulamentar é aquele que assegura ao empregador ditar regras gerais no curso da relação de emprego. Por fim, o poder disciplinar seria um verdadeiro poder punitivo reservado ao empregador na condução de suas atividades econômicas.

O poder diretivo acima mencionado, no entanto, não se confunde com a hierarquia. Hierarquia é a situação na qual uma pessoa fica em posição de inferioridade em relação à outra numa mesma corporação ou organização. Numa relação de chefe e chefiado. Situação de hierarquia, por exemplo, existe nas corporações militares, que se organizam, necessariamente, com base neste princípio.

"A hierarquia importa um poder de senhorio do superior em face do inferior, do qual este não pode unilateralmente livrar-se. Entretanto, o empregado é livre para rescindir o contrato de trabalho" (ROMITA, 1983, p. 46). É o que ocorre, naquela primeira situação, na relação institucional mantida pelo Estado com seus servidores militares, onde estes ficam hierarquicamente sujeitos àquele.

Tal posição não se admite, no entanto, na relação jurídica de natureza contratual. Nesta, um dos contratantes não fica hierarquicamente sujeito à outra. Entre os contratantes há uma relação de igualdade contratual. Entre eles não há hierarquia. Ao menos no plano contratual (SANTOS, 2005, p. 183).

Essa situação de igualdade contratual entre empregado e empregador, no entanto, não se confunde com a posição assumida pelo trabalhador quando ele, por força do contrato, obriga-se a cumprir ordens. E essa situação de fato (subordinação), decorrente do contrato firmado, não se confunde com a relação contratual de igualdade firmada entre os contratantes - empregado e empregador.

Assim, não há hierarquia entre empregado-contratado e empregador-contratante. Existe, sim, uma relação de igualdade entre eles no plano contratual. O que acaba ocorrendo, no entanto, é que, como o empregado se sujeita, por contrato, a receber ordens, alguns veem nesta situação fática (sujeição) uma manifestação de poder por parte do empregador. O "poder" do empregador, entretanto, não passa de uma faculdade jurídica, cuja legitimação decorre do contrato. O poder hierárquico, portanto, numa relação de emprego, não passa de uma faculdade contratual, na qual uma das partes concorda em receber ordem do outro no cumprimento do serviço contratado.

Essa faculdade jurídica, assim, reserva ao empregador o direito de ditar as ordens para que os serviços possam ser executados pelo empregado e, por óbvio, nele se insere o direito de fiscalizar a sua execução. Ditar ordens para a prestação e serviços e físcalizar a execução dos serviços não respaldam, no entanto, a violação aos direitos fundamentais por parte do empregador quando não contratado expressamente; essa faculdade contratual de direção, pois, não assegura ao empregador avançar sobre os direitos fundamentais dos empregados.

Contudo, como conclui Arion Sayão Romita (2014, p. 964), o direito do trabalho, como os demais ramos do direito, gira em torno dos direitos fundamentais, cuja finalidade é o respeito à dignidade da pessoa humana. E os direitos fundamentais tanto limitam o exercício do poder do empregador, como representa uma barreira à flexibilização das condições de trabalho mediante negociação individual e coletiva.

Daí se tem que não se pode respaldar qualquer conduta do empregador ao restringir o direito fundamental do trabalhador por força do que seria seu poder diretivo e fiscalizador da prestação de serviços contratados.

Interessante, ainda, acrescentar que o doutrinador brasileiro que mais defendeu a teoria da instituição, ressalvou que o poder do empregador não interfere nos direitos do "empregado enquanto homem". 
Assim, exemplificativamente, a direção a empresa não poderia, sem mais, exigir por força de seu poder ou impor no regulamento interno, sob pena de sanção disciplinar, que os empregados $\mathrm{s}$ submetessem a revistas antes da saída do estabelecimento, medida explicável a fim de prevenir tentativas de furto, mas que não pode ser realizada por força do direito institucional da empresa, por ferir um direito individual do empregado, diante do qual a autoridade na empresa deve ser curvar (MESQUITA, 1950, p. 55).

Em suma, em regra geral, é a empresa que deve ceder diante do direito fundamental do trabalhador e, não, o inverso. Isso porque a pessoa humana é quem possui dignidade. E as regras constitucionais estão posta a serviço da pessoa física, de modo que todos os demais devem, em regra, submeter-se ao respeito da dignidade da pessoa humana, inclusive do trabalhador.

Desse modo, esse fundamento - poder diretivo empregador - deve ser completamente afastado para justificar qualquer restrição aos direitos fundamentais dos trabalhadores por absoluta falta de consistência científica.

\section{Renúncia a direito fundamental}

Para alcançar a conclusão acima, é preciso, ainda, chamar a atenção para outra questão. Trata-se da renúncia (limite e restrição) ao direito fundamental ou, mais corretamente, da contratação da limitação ao seu exercício (do direito fundamental). E, por certo, essa limitação, a princípio, não pode ser considerada como uma cláusula implícita ao contrato de emprego.

De logo, então, chama a atenção o disposto no art. 11 do Código Civil (BRASIL, 2002), que estabelece que, "Com exceção dos casos previstos em lei, os direitos da personalidade são intransmissíveis e irrenunciáveis, não podendo o seu exercício sofrer limitação voluntária”. Vejam que esse dispositivo estabelece, em outras palavras, que a pessoa não pode transmitir, renunciar ou contratar a limitação dos seus direitos de personalidade, salvo nas hipóteses permitidas em lei.

Aqui o legislador restringiu a autonomia privada com fundamento no princípio da dignidade humana, vedando que a pessoa se autolimite no exercício dos seus direitos fundamentais, em especial os da personalidade.

Contudo, esse dispositivo legal deve ser interpretado de modo a que não se chegue ao ponto de vedar que a pessoa possa contratar derredor dos seus direitos fundamentais, sob pena de negar a própria dignidade que também se concretiza pela liberdade de contratar. Daí porque é aceito, por exemplo, que a pessoa contrate o uso de sua imagem ou contrate posar nua, revelando sua intimidade corporal. Mas isso é permitido porque a legislação civil assim prevê (art. 20 do Código Civil).

Assim sendo, o titular do direito fundamental tem a faculdade de contratar autolimitando voluntariamente o seu exercício, desde que a tanto esteja autorizado por lei. Observe-se, ainda, que a margem de disponibilidade dos direitos fundamentais individuais, por se restringirem à sua esfera individual, é diversa daquela a que se referem os direitos fundamentais sociais, já que estes repercutem também na comunidade em que se insere a pessoa. De qualquer sorte, a vontade deve ser livremente manifestada. E, no contrato de emprego, com raríssimas exceções, o empregado não tem liberdade plena na negociação das cláusulas do ajuste. Isso porque esse contrato deriva de uma relação de poder, na qual um dos polos configura um centro de poder.

Doutrinas nacional e estrangeira, no entanto, são unânimes em afirmar, que, neste caso, é exigível, e mais, é necessário, que a vontade do titular do direito fundamental "seja pleno, efetivo, nunca presumido, atual, espontâneo, consciente, informado...” (MEIRELES, 2009, p. 215). O consentimento aqui há de ser qualificado. E "vontade qualificada é expressa, espontânea, pessoal, atual e esclarecida" (MEIRELES, 2009, p. 215). 
A limitação ao direito fundamental, assim, há de ser "produto inequívoco de uma vontade livre e esclarecida" (ANDRADE, 2012, p. 308), "isenta de erro e inequívoca" (CROCIE, 2013, p. 127).

Neste caso, como ensina Jorge Reis Novais (2006, p. 256),

a declaração e vontade só é válida quando emitida consciente e voluntariamente, numa situação em que quem renuncia está em condições de avaliar todas as consequências da sua decisão e decide tanto quanto possível livre de constrangimentos, ameaças ou coações, mas, mais ainda, quando as partes da relação jurídica se encontrem numa situação de poder negocial equilibrado, em que, no fundo, a renúncia a uma posição de direito fundamental signifique um exercício autônomo de liberdade e não mero disfarce de uma restrição heterônoma não admissível.

José Carlos Vieira de Andrade (2012, p. 308), seguindo esta linha, sustenta que "a manifestação de vontade deve ser esclarecida", sendo válida quando a pessoa tem "conhecimento concreto de todas as consequências relevantes da limitação, e isenta de erro". Neste caso, então, não cabe o consentimento presumido, pois a vontade "deve ser inequívoca", ainda que "aparentemente possa invocar-se o interesse da pessoa" (ANDRADE, 2012, p. 308)

E mesmo à luz das relações jurídicas especiais ou "relações especiais de poder" essas lições de aplicam. José Joaquim Gomes Canotilho (2002, p. 458), por exemplo, leciona que, mesmo nestes casos, a exemplo, da relação jurídica militar, o entendimento de que haveria renúncia ao direito fundamental ao se inserir na corporação

é uma concepção ultrapassada: (a) um militar, um funcionário, um estudante, ao ingressarem em certas relações especiais, não renunciam a qualquer direito, sendo o recurso à ideia de sujeição voluntária e de abdicação de direitos a face oculta de sobrevivência absolutista do 'domínio do Estado' sobre os 'súditos' ao seu serviço; (b) mesmo a aceitar-se uma dimensão voluntária de restrição e direitos, a vontade pura do particular não pode conduzir a uma relativização completa do princípio da reserva da lei.

Na mesma linha, Jorge Reis Novais (2006, p. 255) sustenta que, nestes casos, havia entendimento de que quanto a renúncia do direito fundamental com "base na pretensa existência de uma declaração de vontade, presumida ou ficta" tão somente pela parte se sujeitar "voluntariamente à relação especial".

Contudo, essa doutrina, "hoje considerada ultrapassada", é “dificilmente sustentável”. Isso porque se confunde o ingresso, livre ou obrigatório na instituição, com uma presumida aceitação de restrições aos direitos fundamentais (NOVAIS, 2006, p. 255).

Vejam, então, que, mesmo nas relações especiais de poder, na qual a pessoa mantém relação com o Estado, ele, ao ingressar no serviço público, não renuncia ao seu direito fundamental, salvo se por disposição expressa, consciente e qualificada. Logo, tal renúncia implícita jamais pode ocorrer numa relação de natureza privada, ainda que uma das partes seja detentor de certa posição de poder (econômico ou social).

É certo, porém, que "casos extremos a vontade de aceitação da restrição [ao direito fundamental] pode se presumida" (NOVAIS, 2006, p. 256). É o que pode ocorrer, por exemplo, em relação a uma pessoa gravemente enferma e inconsciente, situação na qual se pode presumir a sua autorização para, v.g., amputar uma perna como tentativa de salvar-lhe a vida.

A vontade presumida (ou implícita), assim, somente seria admissível em casos extremos.

Daí se tem que não encontra respaldo em qualquer interpretação constitucional a conclusão de que o trabalhador, ao celebrar o contrato de emprego, estaria, presumida ou 
implicitamente, conferindo poderes para que o empregador possa adotar conduta para restringir o direito fundamental do trabalhador.

Aliás, em rara decisão do STF (BRASIL, 1999) a respeito, esta Corte conclui por manter decisão que considerou legítima a revista pessoal

... colocada em prática com resguardo dos atributos da dignidade da pessoa, sem constrangimentos, mas, de modo previamente divulgado e aprovado pelo empregado da empresa. Tal conduta, quando processada segundo os padrões éticos, com discrição, privacidade, respeitando e preservando a essência dos valores morais do ser humano, não deve ser, só por si, chamada de afrontosa ou agressiva à dignidade pessoal.

Vejam, então, que o próprio STF teve como lícita a revista (violação à intimidade) que estaria, no caso concreto, prevista em norma interna da empresa (a qual o trabalhou aderiu). Logo, apenas admitiu a sua possibilidade mediante prévia contratação expressa (documentada), ainda que por adesão à norma interna da empresa (o que atrai sua análise do ponto de vista da manifestação da declaração de vontade qualificada).

Assim, parcialmente podemos concluir que não se pode admitir que a restrição ao direito fundamental com base em cláusula que se alega ser inerente e implícita ao contrato de emprego.

Aqui, em verdade, confunde-se a cláusula implícita ao contrato que confere a faculdade de dirigir e fiscalizar (não é preciso expressa disposição neste sentido), com a cláusula na qual o trabalhador, eventualmente, auto se limita no exercício de seus direitos fundamentais (a exigir cláusula expressa).

Daí se conclui que práticas como a de revistar os trabalhadores, ainda que seja em seus pertences (bolsas, mochilas, etc), utilizar de sua imagem, acessar seus dados bancários, violar e publicar suas comunicações privadas, etc, revelam-se abusivas quando não estão respaldadas por cláusula contratual expressamente pactuada pelo empregado.

Vale destacar, ainda, que o contrato de trabalho serve de instrumento para pactuação dos direitos fundamentais (MEIRELES, 2014, p. 157) ainda, que os inespecificamente trabalhistas, isto é, aqueles que são assegurados a todas as pessoas, inclusive à pessoa do empregado (GUTIÉRREZ, 2011, p. 128).

É preciso chamar, ainda, a atenção para outra questão: é que, ainda que haja concordância expressa do empregado com a restrição ao direito fundamental, o pacto respectivo pode se revelar abusivo se dele não decorrer qualquer vantagem para o trabalhador. Ou seja, a limitação ao direito fundamental não pode se restringir a simples renúncia de direitos, sem qualquer contrapartida. Neste caso, uma vez constatada a gratuidade da cessão da parcela dos seus direitos fundamentais, pode-se, ainda, concluir pela abusividade do pacto individual, já que com ele o trabalhador em nada seria beneficiado, configurando-se em simples renúncia destituída de qualquer benefício ao detentor do direito fundamental.

A cessão do direito de forma graciosa e gratuita, em verdade, numa relação de emprego, acaba por configurar hipótese de enriquecimento ilícito, à medida em que o empregador, ao se beneficiar do direito de outrem, pode obter vantagem sem garantir ao detentor da garantia fundamental qualquer compensação à cessão da parcela do seu bem jurídico protegido constitucionalmente.

Por fim, deve ser ressaltado que, em algumas hipóteses, por óbvio, que, dada a própria essência da obrigação contratada de prestar serviços sob especiais condições, é inerente se entender a limitação ao direito fundamental. É o que ocorre, por exemplo, em empresas de tendência ou em serviços nas quais a intimidade e privacidade do trabalhador são objeto de cessão (artistas-empregadas que se exibem nuas, etc). 


\section{Limitação ao direito fundamental mediante negociação coletiva}

As lições anteriores, no entanto, podem ser contornadas quando diante de limitação ou restrição ao direito fundamental posta em norma coletiva do trabalho. Isso porque, por sua própria natureza, a norma coletiva (convenção ou acordo coletivo do trabalho) sempre é pactuada de forma expressa. E mais, ela é aprovada pelas partes diretamente interessadas e representadas pelas entidades sindicais, ainda que sejam mediante assembleia dos trabalhadores interessados.

É preciso, porém, ressaltar que, mesmo nesta hipótese de contratação coletiva, é preciso que haja uma compensação de vantagens. Não se pode, assim, aceitar a simples renúncia ou cessão de direitos fundamentais pelos trabalhadores, ainda que mediante acerto coletivo, sem que haja uma contrapartida.

E é neste sentido que decidiu o STF (BRASIL, 2016) (repercussão geral tema n. 152) quando esta Corte conclui que

a Constituição reconheceu as convenções e os acordos coletivos como instrumentos legítimos de prevenção e de autocomposição de conflitos trabalhistas; tornou explícita a possibilidade de utilização desses instrumentos, inclusive para a redução de direitos trabalhistas; atribuiu ao sindicato a representação da categoria; impôs a participação dos sindicatos nas negociações coletivas; e assegurou, em alguma medida, a liberdade sindical...

Tudo isso, porém, com contrapartida em favor do trabalhador.

No mesmo sentido, já a partir deste precedente citado anteriormente, o mesmo STF (BRASIL, 2016) teve como válido o acordo coletivo do trabalho no qual foi suprimido o pagamento das horas in itinere e, "em contrapartida", foram "concedidas outras vantagens aos empregados, "tais como 'fornecimento de cesta básica durante a entressafra; seguro de vida e acidentes além do obrigatório e sem custo para o empregado; pagamento do abono anual aos trabalhadores com ganho mensal superior a dois salários-mínimos; pagamento do salário-família além do limite legal; fornecimento de repositor energético; adoção de tabela progressiva de produção além da prevista na Convenção Coletiva".

Neste caso se decidiu que, "ainda que o acordo coletivo de trabalho tenha afastado direito assegurado aos trabalhadores pela CLT, concedeu-lhe outras vantagens com vistas a compensar essa supressão". Logo, válida essa norma coletiva, já que eventual restrição ao direito fundamental (na hipótese, pagamento de salário) foi objeto de expressa contratação e de específicas compensações. Não se cuidou, portanto, de simples cessão de direito sem qualquer contrapartida.

\section{Princípio do não retrocesso social}

Às lições cabe, ainda, acrescentar um outro fundamento. É que a contrapartida é exigível, seja na pactuação individual, como na coletiva, já que a Constituição Federal, no caput do art. $7^{\circ}$, estabeleceu que são direitos dos trabalhadores as prestações jusfundamentais ali previstas, além das demais asseguradas na Carta Magna, bem como outros que "visem à melhoria de sua condição social".

Como é sabido, ultrapassada a fase do Estado Liberal, assumindo o Poder Público sua versão Social e Democrática (o Estado Democrático de Direito Social), criou-se com ele um sentimento, inerente a todas as constituições sociais, de que as conquistas sociais não retroagem. Em suma, os direitos fundamental-sociais, as liberdades públicas, etc, sempre tendem a avançar, não se admitindo retrocesso.

Mas essas conquistas não se fazem apenas através de normas constitucionais. Os avanços obtidos pela via infraconstitucional, concretizando direitos fundamentais elencados na 
Constituição, também tendem ao avanço, não se admitindo o retrocesso através das normas ordinárias, já que este iria contra a própria natureza da constituição social. Veda-se, assim, a "contrarrevolução social" ou a "evolução reacionária" (CANOTILHO, 2002, p. 336).

O princípio do não-retrocesso social no direito do trabalho brasileiro, por sua vez, foi escancaradamente acolhido no texto constitucional, embora a só adoção do modelo de estado de bem-estar social já fosse suficiente para tanto. Ele se extrai do caput do art. $7^{\circ}$ da Carta da República que, em sua parte final, estabelece que são direitos dos trabalhadores aqueles elencados em seus diversos incisos, "além de outros que visem à melhoria de sua condição social".

Ora, o que o legislador constitucional estabeleceu, no art. $7^{\circ}$, foi uma série mínima e fundamental de direitos social-trabalhistas, preceituando, ainda, que outros direitos podem ser concedidos aos trabalhadores, desde que "visem à melhoria de sua condição social”. Daí se tem que não se pode admitir norma constitucional derivada (emenda) ou norma infraconstitucional que tenda a não gerar uma melhoria na condição social do trabalhador. Ela seria inconstitucional por justamente não preencher esse requisito constitucional da melhoria da condição social do trabalhador.

Daí se tem que nem por acordo individual, nem por norma coletiva, bem como por lei infraconstitucional ou reforma constitucional, pode-se contratar ou legislar de forma mais desfavorável ao trabalhador, já que, neste caso, incorre-se em conduta inconstitucional, haja vista a vedação ao retrocesso social na área trabalhista (direito que não vise à melhoria da condição social do trabalhador).

O caput do art. $7^{\circ}$ da Constituição Federal de 1988, portanto, acabou de forma expressa acolhendo o princípio do não retrocesso social (ou do avanço social) na seara do direito do trabalho, ao assegurar outros direitos que visem a melhora da condição social do trabalhador, vedando a contratação ou a legislação contrária. E ao agasalhar esse princípio, ele acabou por limitar a autonomia da vontade, de modo a impedir a contratação individual ou coletiva de forma mais desfavorável ao trabalhador.

É certo, porém, que, não restará configurado o retrocesso social se, a partir do acordado individual ou coletivamente, for o trabalhador devidamente compensado quando da cessão de parcela de seus direitos já consolidados.

Neste sentido, José Joaquim Gomes Canotilho (2002, p. 336) ensina que:

O princípio da proibição de retrocesso social pode formular-se assim: o núcleo essencial dos direitos sociais já realizado e efetivado através de medidas legislativas (...) deve considerar-se constitucionalmente garantido, sendo inconstitucionais quaisquer medidas estaduais que, sem a criação de outros esquemas alternativos ou compensatórios, se traduzam, na prática, numa 'anulação', 'revogação' ou 'aniquilação' pura a simples desse núcleo essencial.

Assim, a limitação do direito fundamental por norma coletiva somente encontrará respaldo se contornada por "outros esquemas alternativos ou compensatórios" (CANOTILHO, 2002, p. 336) ao direito social objeto de modificação ou supressão. Logo, ter-se-á como inconstitucional qualquer ato ou lei "que, sem a criação de outros esquemas alternativos ou compensatórios, se traduzam, na prática, numa anulação, revogação ou aniquilação pura a simples" do núcleo essencial dos direitos fundamentais dos trabalhadores, sejam eles específicos (trabalhistas) ou inespecíficos (TOSCANI, 2016, considerando estes últimos como aqueles assegurados a qualquer pessoa, inclusive ao trabalhador (PALOMEQUE, 2003, p. 173).

Daí se tem que o legislador constitucional estabeleceu, no art. $7^{\circ}$ da Constituição de 1988, foi uma série mínima e fundamental de direitos social-trabalhistas, preceituando, ainda, que outros direitos podem ser concedidos aos trabalhadores, desde que "visem à melhoria de sua condição social”. Logo se tem que não se pode admitir norma constitucional derivada (emenda), 
norma infraconstitucional, norma coletiva trabalhista ou norma contratual que tenda a não gerar uma melhoria na condição social do trabalhador.

\section{Conclusão}

Diante do argumentado acima, cabe concluir que o simples poder (faculdade) de direção e de fiscalização não assegura ao empregador o direito de limitar ou restringir os direitos fundamentais dos trabalhadores numa relação de emprego.

Outrossim, em regra, para que se imponha uma restrição ou limite ao exercício do direito fundamental, com muito mais razões numa relação de emprego, já que uma das partes se encontra em estado de sujeição à outra, é preciso que a vontade do trabalhador seja fruto inequívoco de sua vontade livre e esclarecida, isenta de qualquer vício ou erro.

É certo que o titular do direito fundamental tem a faculdade de contratar autolimitando voluntariamente o seu exercício, desde que a tanto esteja autorizado por lei. A vontade, porém, de se auto restringir em seu direito fundamental, deve ser livre e expressamente manifestada.

No contrato de emprego, com raríssimas exceções, o trabalhador, tratando diretamente com o empregador, tem liberdade plena na negociação das cláusulas do ajuste. Essa conclusão se extrai do fato de que o contrato de emprego deriva de uma relação de poder, na qual o empregador é detentor de "poderes" que colocam o trabalhador numa situação de sujeição.

Assim, na interpretação das cláusulas contratuais, ainda que derivada de ajustes tácitos, deve-se interpretar em favor do direito fundamental, procurando preservá-lo contra condutas abusivas por parte de outro contraente.

Deve ficar bem claro, ainda, que a limitação ou restrição ao direito fundamental não pode ser gracioso, ou seja, cuidar-se de simples de renúncia de parcela do direito fundamental sem qualquer contrapartida ou benefício em favor do trabalhador, sob pena, inclusive, de configuração do enriquecimento ilícito.

É de se ressaltar que essa limitação ou restrição ao direito fundamental dos trabalhadores pode ser objeto de negociação coletiva, desde que não configure simples renúncia de direitos, sem qualquer contrapartida compensatória. Neste caso, portanto, nem por vontade coletivamente pactuada se admite a cessão da proteção constitucional sem a devida compensação.

Por fim, como maior fundamento à proibição da limitação ou cessão de direitos fundamentais trabalhistas, deve ser lembrado que, ao menos na seara do direito do trabalho, a Constituição agasalhou o princípio do não retrocesso social ao assegurar a pactuação de outros direitos que visem à melhoria social do trabalhador, o que impedira a supressão de vantagens sem a devida medida compensatória.

\section{Referências}

ANDRADE, José Carlos Vieira de. Os direitos fundamentais na Constituição Portuguesa de 1976. 5. ed. Coimbra: Almedina, 2012.

BAYLOS, Antonio. Direito do trabalho: modelo para armar. São Paulo: LTr, 1999.

BRASIL.Decreto-lei n ${ }^{\circ} 5.452$, de $1^{\circ}$ de maio de 1943. Aprova a Consolidação das Leis do Trabalho. Disponível em: http://www.planalto.gov.br/ccivil_03/decreto-lei/Del5452.htm. Acesso em: 03 abr. 2017.

BRASIL. Constituição da República Federativa do. 1988. Disponível em: http://www.planalto.gov.br/ccivil_03/constituicao/constituicaocompilado.htm. Acesso em: 03 abr. 2017. 
BRASIL.Lei $\mathrm{n}^{\mathrm{o}}$ 10.406, de 10 de janeiro de 2002.Institui o Código Civil. Disponível em: http://www.planalto.gov.br/ccivil_03/leis/2002/L10406.htm. Acesso em: 03 abr. 2017.

BRASIL.Supremo Tribunal Federal.Agravo regimental em agravo de instrumento n. 220.459. Relator: Ministro Moreira Alves. Brasília, 28 set. 1999. Diário de Justiça 29 out. 1999, p. 04. Disponível em: http://www.stf.jus.br/portal/jurisprudencia/listarJurisprudencia.asp?s1=\%28AI\%24.SCLA.+E+22 0459.NUME.\%29+OU+\%28AI.ACMS.+ADJ2+220459.ACMS.\%29\&base=baseAcordaos\&url= http://tinyurl.com/nn49eye. Acesso em: 04 abr. 2017.

BRASIL.Supremo Tribunal Federal.Recurso extraordinário 590.415. Relator Ministro Roberto Barroso, Brasília 30 abr. 2015. Diário de Justiça Eletrônico. Disponível em: http://redir.stf.jus.br/paginadorpub/paginador.jsp?docTP=TP\&docID=8590961. Acesso em: 03 abr. 2017.

BRASIL.Supremo Tribunal Federal.Recurso extraordinário 895.759. Relator Ministro Teori Zavascki, Brasília 08 set. 2016. Diário de Justiça Eletrônico. Disponível em: http://www.stf.jus.br/portal/jurisprudencia/listarJurisprudencia.asp?s1=\%28RE\%24.SCLA.+E+8 95759.NUME.\%29+NAO+S.PRES.\&base=baseMonocraticas\&url=http://tinyurl.com/okagalc. Acesso em: 03 abr. 2017.

CANOTILHO, José Joaquim Gomes. Direito constitucional e teoria da constituição. 5. ed. Coimbra: Almedina, 2002.

CATHARINO, José Martins. Compêndio universitário de direito do trabalho. v. I. São Paulo: Jurídica, 1972.

COUTINHO, Aldacy Rachid. Função social do contrato individual do trabalho. In: Transformações do direito do trabalho. Dallegrave Neto, José Afonso (coord.). Curitiba: Juruá, 2000 .

CROCIE, Benedita Mac. Os limites da renúncia a direitos fundamentais nas relações entre particulares. Coimbra: Almedina, 2013.

DELGADO, Maurício Godinho. Contrato de Trabalho. Caracterização, distinções, efeitos. São Paulo: LTr, 1999.

DELGADO, Maurício Godinho. O poder empregatício. São Paulo: LTr, 1996.

GITIÉRREZ PÉREZ, Miguel. Ciudadanía en la empresa y derechos fundamentales inespecíficos. Murcia: Laborium, 2011. 266 p. ISBN 978-84-92602-34-6

MAGANO, Octávio Bueno. Manual de direito do trabalho. v. 2. 2 ed. São Paulo: LTr, 1988.

MEIRELES, Edilton. A constituição do trabalho. O trabalho nas Constituições da Alemanha, Brasil, Espanha, França, Itália e Portugal. 2. ed. São Paulo: LTr, 2014. 
MEIRELES, Rose Melo Venceslau. Autonomia privada e dignidade humana. Rio de Janeiro: Renovar, 2009,

MESQUITA, Luiz José de. Direito disciplinar do trabalho, uma interpretação institucionalista do direito do trabalho. São Paulo: Saraiva, 1950.

MESQUITA, Luiz José de.Direito disciplinar do trabalho. 2 ed. São Paulo: LTr, 1991.

MORAES FILHO, Evaristo de. Influência do direito alemão no direito brasileiro do trabalho, In: Temas atuais de trabalho e previdência. São Paulo: LTr, 1976, p. 81-99.

MORAES FILHO, Evaristo de. Introdução ao direito do trabalho. 4. ed. São Paulo: LTr, 1986.

NASCIMENTO, Amauri Mascaro. Curso de direito do trabalho. 8. ed. São Paulo: Saraiva, 1989.

NASCIMENTO, Amauri Mascaro. Teoria geral do direito do trabalho. São Paulo: LTr, 1998.

NOVAIS, Jorge Reis. Renúncia a direitos fundamentais. In: Direitos fundamentais, trunfos contra a maioria. Coimbra: Coimbra Editora, 2006.

PALOMEQUE LÓPEZ, Manuel Carlos. Los derechos laborales inespecíficos. In: Minerva. Revista de Estudos Laborais, ano I, n. 2, Coimbra: Almedina, 2003, p. 173-194.

PEREIRA, Adilson Bassalho. A subordinação como objeto do contrato de emprego. São Paulo: LTr, 1991.

QUINTAS, Paula do Couto. Os direitos de personalidade consagrados no Código do Trabalho na perspectiva exclusiva do trabalhador subordina - direitos (des)figurados. Coimbra: Almedina, 2013. 433p. ISBN 978-972-40-5135-2

ROMITA, Arion Sayão. O fascismo no direito do trabalho brasileiro. São Paulo: LTr, 2001.

ROMITA, Arion Sayão. O poder disciplinar do empregador. Rio de Janeiro: Freitas Bastos, 1983.

ROMITA, Arion Sayão. Poderes do empregador e ideologia. Revista LTr, ano 78, vol. 8, agosto de 2014.

SANTOS FERNÁNDEZ, Maria Dolores. El contrato de trabajo como limite al poder del empresário. Albacate: Bomarzo, 2005.

SUPIOT, Alain. Critique du droit du travail. Paris: Quadrige/PUF, 2002.

SÜSSEKIND, Arnaldo Lopes et allii. Direito do trabalho brasileiro. Rio de Janeiro: Jacinto Editora, 1943.

TOSCANI GIMÉNEZ, Daniel. Valenciano sal, Antonio.Derechos fundamentales inespecíficos de los trabajadores. Albacete: Bomarzo, 2016. 129p. ISBN 978-84-16608-43-0 